\title{
Why do pregnant women present late for their first antenatal care consultation in Cameroon?
}

\author{
Paul Nkemtendong Tolefac ${ }^{1,2^{*}}$, Gregory Edie Halle-Ekane ${ }^{2,3}$, Valirie Ndip Agbor ${ }^{4}$, Carlson Barbila Sama ${ }^{5}$, \\ Calypse Ngwasiri ${ }^{6}$ and Pierre Marie Tebeu ${ }^{1}$
}

\begin{abstract}
Background: Early initiation of antenatal care visits is an essential component of services to improving maternal and new born health. The Cameroonian Demographic and Health Survey conducted in 2011 indicated that only 34\% of pregnant women start antenatal care in the first trimester. However, detailed study to identify factors associated with late initiation of care has not been conducted in Cameroon. The aim of this study was to assess the prevalence of late booking first ANC visit amongst attendance of first ANC and the determinants of late first ANC in Douala general hospital.

Methods: It was a cross sectional analytic study over the period of 5 months in Douala general hospital. The study subjects were pregnant women visiting the facilities for the first time during the index pregnancy. Data were collected using pre-tested questionnaire. Logistic regression analysis was done to identify factors associated with late first ANC with the level of significance set at 0.05 .

Results: A total of 293 women participated in the study; 129 (44.0\%) of them came for their first ANC visit late, after 12 weeks of gestation. Most common reasons for coming late for first ANC were financial constraints $(34.5 \%, 45)$ and long distance to the hospital $(34.5 \%, 45)$. Factors associated with late start of first ANC after logistic regression were: family size greater than $4(\mathrm{OR}=2,95 \% \mathrm{Cl}=1.25-3.19, p$ value $=0.004)$, long distance to the hospital $(\mathrm{OR}=1.84,95 \% \mathrm{Cl}=1.1-3.07$, $\mathrm{p}$ value $=0.02)$ and low monthly income level less than 200US dollars $(\mathrm{OR}=3.2,95 \% \mathrm{Cl}=1.33-3.54, \mathrm{p}$ value $=0.002)$.

Conclusion: About half of pregnant women do not start ANC early in the first trimester largely due to large family size, low monthly income and long distance to the hospital.
\end{abstract}

Keywords: Antenatal care, Late ANC, Booking, Determinants

\section{Background}

Globally, the maternal mortality rate (MMR) fell by nearly $44 \%$ over the past 25 years, to an estimated 216 maternal deaths per 100,000 live births in 2015. Developing regions accounted for approximately $99 \%(302,000)$ of this estimated global maternal deaths in 2015, with sub-Saharan Africa alone accounting for roughly $66 \%(201,000)$. This 2015 reports estimates MMR in Cameroon at 596 maternal deaths per 100,000 live births [1,2]. In 2015, countries

\footnotetext{
* Correspondence: ptolefac15@gmail.com; ptolefac@gmail.com

${ }^{1}$ Faculty of Medicine and Biomedical Sciences, University of Yaounde 1,

Yaounde, Cameroon

Obstetric and Gynaecology service, Douala General Hospital, Douala, Cameroon

Full list of author information is available at the end of the article
}

met and put forward a series of goals known as sustainable development goals (SDGs). SDG 3 calls for the acceleration of current progress in order to achieve a global MMR of 70 maternal deaths per 100,000 live births in 2030 [3]. This global reduction of MMR and a positive pregnancy outcome can only be achieved if the care offered to women during pregnancy improve and they initiates antenatal care (ANC) early enough $[4,5]$. Antenatal care refers to the care that is given to an expectant mother from the time that pregnancy is confirmed until the onset of labour. This care enables the promotion of a positive pregnancy outcome. The components of ANC include: risk identification; prevention and management of pregnancy-related or concurrent diseases; and health 
education and health promotion [4]. Recently in 2016, WHO recommends a minimum of eight ANC contacts during pregnancy and that the first contact should be done before the 12th week of gestation $[4,6]$. Planning for a safe delivery is an integral part of ANC.

According to WHO, early ANC refers to initiation of antenatal care as soon as possible after confirmation of pregnancy and or within the first 12 weeks of gestation whereas late ANC is starting ANC after 12 weeks of gestation [4]. Early initiation of antenatal care play a major role in detecting and treating some complications of pregnancy and forms a good basis for appropriate management during delivery and after childbirth. Failure to attend antenatal care early results in the potential for complications during pregnancy, delivery, and puerperium and hence increasing MMR [6, 7]. Existing evidence from most developing countries indicates that few women seek ANC services early in the course of pregnancy [8-11]. Late initiation of ANC has been associated to: maternal education, unemployment, lack of knowledge or misconceptions about the value/purpose of antenatal care, marital status, socioeconomic status, financial constraints [10]. The rate of early booking ANC visits in Cameroon is low, as is evident by the Demographic and Health Survey (DHS) report in 2011 where only $34 \%$ of pregnant women did a booking visit within the first trimester [12]. Halle et al. reported a similar prevalence of $27.2 \%$ in a health centre in Buea [13]. These findings therefore demonstrates that late initiation of ANC visit is a major public health concern in Cameroon. To the best of our knowledge, no study has been conducted to identify the determinants of late first ANC booking in Cameroon. This study seeks to determine the prevalence and determinants of late initiation of ANC among ANC attendants presenting for their first visit in Douala General Hospital (DGH).

\section{Methods}

\section{Study design and setting}

This was a cross sectional analytic study conducted between January and May 2017 in Douala general hospital (DGH), Cameroon. DGH is a tertiary university teaching hospital located in the economic capital of Cameroon, Douala. It is one of the fastest growing hospitals in the central African sub region. This Hospital has a service of obstetrics and gynaecology. This service runs antenatal care (ANC) outpatient clinic with a team made up of seven obstetricians and gynaecologists. The ANC clinic receives patients from Douala and its environs including referral cases from other hospitals.

\section{Participants}

All consenting participants presenting for their first ANC visit with confirmed pregnancy were consecutively recruited, irrespective of the gestational age. Participants whose gestational age could not be determined, and those who refused to give their informed consent were excluded from the study.

\section{Variables}

Data were collected using structured questionnaire, which was developed based on the Cameroonian Demographic and Health Survey (DHS) data collection tool and other relevant literature. The questionnaire was first developed in English and later translated into French. The information collected included sociodemographic background of mothers (e.g. age, marital status, level of education, distance from the hospital, income level, and profession obstetric history (gravid status, parity, gestational age) and reasons for presenting late. After collection, the data was entered into epi-data and then exported to SPSS version 20.0 for analysis.

\section{Sample size and sampling}

The minimum sample size was calculated using the Lorenz formula [14] and the prevalence of women who started ANC late after 12 weeks in Cameroon at $66 \%$ according to the 2011 Cameroonian DHS [12], this minimum sample size was estimated at 345 participants. In this index study described herein, the consecutive and convenient non probability sampling technique was used where all pregnant women presenting for their first antenatal care were recruited.

\section{Statistical methods}

This data was analysed using SPSS version 20.0. Continuous variables were presented are as means and standard deviations and categorical variables as frequencies and percentages. The proportion of late first ANC attendants was determined and the 95\% confidence interval of the main outcome variable was calculated to show the extent of late initiation of ANC visit at the cutoff point of 12 weeks. The association of independent variables with late ANC initiation was examined by calculating the odds ratios. Nine variables were examined independently using a bivariate analysis.

\section{Ethical considerations}

Ethical and administrative approval were obtained from Douala general hospital. Written informed consent was obtained from all those who participated in the study.

\section{Results}

We approached a total 308 women during their booking ANC. Fifteen women were excluded as shown on the recruitment flow chart on Fig. 1 below. We finally retained 293 women for the study. The mean gestational age at booking was 14 weeks \pm 1.2 weeks. While Table 1 shows 


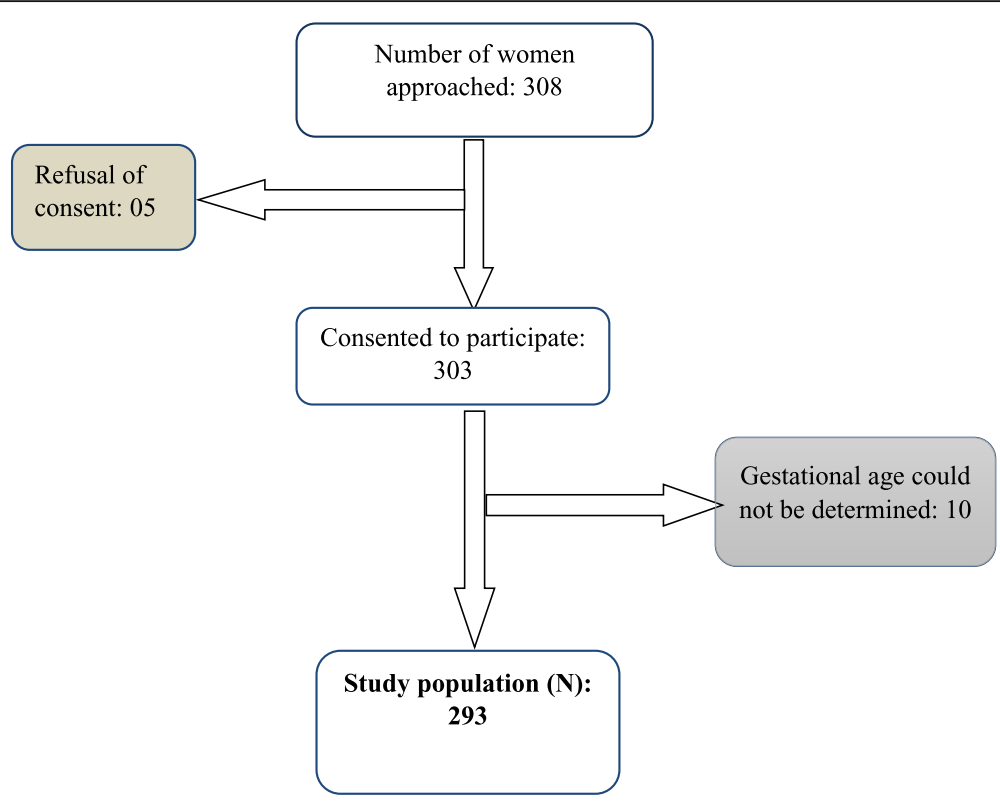

Fig. 1 Flow chart showing recruitment of participants

Table 1 Baseline characteristics of the study population

\begin{tabular}{llll}
\hline Category & Characteristics & Frequency (N) & Percentage (\%) \\
\hline Age distribution & $16-25$ & 83 & 28.3 \\
& $26-35$ & 180 & 61.4 \\
Marital status & $36-45$ & 30 & 10.3 \\
& Married & 114 & 38.9 \\
& Single & 179 & 61.1 \\
Level of education & No formal education & 6 & 2.0 \\
& Primary & 25 & 8.5 \\
& Secondary & 118 & 40.3 \\
Occupation & University & 144 & 49.1 \\
of woman & Employed & 130 & 44.4 \\
Occupation & Not employed & 163 & 55.6 \\
of partner & Employed & 271 & 92.5 \\
Gravid status & Not employed & 22 & 7.5 \\
& Primigravida (1) & 106 & 36.2 \\
& Multigravida (2-4) & 152 & 51.9 \\
& Grand multigravida & 35 & 11.9 \\
Parity & ( $\geq 5)$ & & 43.0 \\
& Nullipara (0) & 126 & 124.0 \\
& Paucipara (1-2) & 124 & 38.0 \\
& Multipara (3-4) & 38 & 1.7
\end{tabular}

The mean age at presentation for first ANC was $27.8 \pm 5.4$ years with about a $3 / 5$ of the participants $26-35$ years. Table 1 shows the distribution of baseline sociodemographic and obstetric characteristics of participants at presentation the baseline characters of women attending ANC in this hospital, Table 2 shows reasons these women frequently announced for late initation of ANC.

\section{Determinants of late first ANC}

As shown on Table 3, the determinants of late first ANC included: family size greater than $4(\mathrm{OR}=2,95 \% \mathrm{CI}=$ $1.25-3.19, p$ value $=0.004)$, long distance to the hospital $(\mathrm{OR}=1.84,95 \% \mathrm{CI}=1.1-3.07, \mathrm{p}$ value $=0.02)$ and low monthly income level less than 200US $(\mathrm{OR}=3.2$, 95\% $\mathrm{CI}=1.33-3.54, p$ value $=0.002$ ).

\section{Discussions}

The result of the cross sectional study among ANC attendants in DGH who presented for their booking visit show that $44.0 \%$ presented late. The most common reasons advanced for late start of first ANC were financial difficulties, busy schedules and long distance to the hospitals. Three factors were associated with late first ANC: large family size, distance to the hospital. The prevalence of late first ANC amongst first ANC attendants of 44.0\% means that almost half of pregnant women in this reference hospital starts their ANC late. This contradicts findings gotten earlier by Halle et al. [13] in a rural health centre in Cameroon where only 27\% started their first ANC during the first trimester versus $73 \%$ that started their first ANC late [13]. The difference could be explained by the fact that Halle et al. conducted their study in a health centre located in a semi-urban area (Buea) whereas we conducted our study in a reference hospital in an urban area (Douala) as the community in 
Table 2 Reasons of late first ANC in the 129 participants who started booking ANC after 12 weeks

\begin{tabular}{lll}
\hline Reason & Frequency & Percentage \\
\hline Financial difficulties & 45 & 34.5 \\
Busy schedule & 25 & 19.4 \\
Uncertainty of pregnancy & 9 & 7.0 \\
Fatigue & 3 & 2.3 \\
Unawareness of gestational age & 2 & 1.6 \\
Laziness & 8 & 6.2 \\
Thought this was the right time to come & 12 & 9.3 \\
Long distance to the hospital & 45 & 34.5 \\
In apparent good health & 18 & 14.0 \\
\hline
\end{tabular}

The mean gestational age at booking was 14 weeks \pm 1.2 week. Amongst the 293 first ANC attendants, 129 participants (44.0\%) started their booking ANC late (after 12 weeks of gestation). As shown on Fig. 2, for those who started their first ANC late, $68.2 \%$ (30.0\% of total) started between 20th -28th of gestation. The commonest reasons of late first ANC advanced by these 129 participants were financial difficulties $(34.5 \%, 45)$, long distances to the hospital $(34.5 \%, 45)$ and busy schedule $(19.4 \%, 25)$. Other reasons advanced by these women for late initiation of ANC are as shown on Table 2
Douala may have better awareness compared to the community in Buea. The very high prevalence of $73 \%$ gotten by Halle et al. [13] could also be explained by the fact that their prevalence of $73 \%$ was gotten amongst all ANC attendants whereas ours was only amongst first ANC attendants. The results are also different from the 2011 report of the Cameroonian DHS where the percentage of pregnant women who started their first ANC during the first trimester was $34 \%$ versus $66 \%$ who started their first ANC late [12]. This could be explained by the five-year time difference between the two studies and hence a possible amelioration. The results are similar to those obtained recently in 2016 and 2017 by authors elsewhere in sub-Sahara Africa where the prevalence of late first ANC ranges between 42 and 56\% $[6,15,16]$.

Varied reasons were advanced for late antenatal booking including financial constraints, long distances to the hospital, and busy schedule with the commonest reason being financial constraints (34.5\%) and busy schedule

Table 3 Determinants of first ANC using univariate logistic regression

\begin{tabular}{|c|c|c|c|c|c|}
\hline \multirow[t]{2}{*}{ Category } & \multirow[t]{2}{*}{ Characteristic } & \multicolumn{2}{|l|}{ First ANC } & \multirow[t]{3}{*}{ OR $(95 \% \mathrm{Cl})$} & \multirow[t]{3}{*}{$p$ value } \\
\hline & & $\leq 12$ weeks $(N=164)$ & $>12$ weeks $(N=129)$ & & \\
\hline & & Number (\%) & Number (\%) & & \\
\hline \multirow[t]{3}{*}{ Age distribution } & $16-25$ & $53(32.3)$ & $30(23.3)$ & 1 & \\
\hline & $26-35$ & $92(56.1)$ & $88(68.2)$ & $1.21(0.75-1.96)$ & 0.430 \\
\hline & $36-45$ & 19 (11.6) & $11(8.5)$ & $0.71(0.45-1.11)$ & \\
\hline \multirow[t]{2}{*}{ Marital } & Married & $64(39.0)$ & $50(38.8)$ & 1 & \\
\hline & Single & $100(61.0)$ & $79(61.2)$ & $0.99(0.62-1.59)$ & 0.963 \\
\hline \multirow[t]{4}{*}{ Level of education } & Primary & $14(8.5)$ & $11(8.5)$ & 1 & \\
\hline & No formal education & $1(0.6)$ & $5(3.9)$ & $0.80(0.43-1.52)$ & 0.350 \\
\hline & Secondary & $62(37.8)$ & $56(43.4)$ & $1.26(0.79-2.02)$ & 0.330 \\
\hline & University & $87(53.1)$ & $57(44.2)$ & $0.701(0.44-1.11)$ & 0.132 \\
\hline \multirow[t]{2}{*}{ Occupation of woman } & Not employed & $82(50.0)$ & $81(62.8)$ & $1.27(0.69-2.35)$ & 0.445 \\
\hline & Employed & $82(50.0)$ & $48(37.2)$ & 1 & \\
\hline \multirow[t]{3}{*}{ Gravid status } & Multigravida (2-4) & $79(48.2)$ & $73(56.6)$ & 1 & \\
\hline & Primigravida (1) & $63(38.4)$ & $43(33.3)$ & $0.80(0.50-1.30)$ & 0.369 \\
\hline & Grand multigravida $(\geq 5)$ & $22(13.4)$ & $13(10.1)$ & $0.32(0.35-1.50)$ & 0.383 \\
\hline \multirow[t]{4}{*}{ Parity } & Multipara (2-4) & $22(13.4)$ & $16(12.4)$ & 1 & \\
\hline & Nullipara (0) & $77(47.0)$ & $49(38.0)$ & $0.69(0.43-1.11)$ & 0.124 \\
\hline & Paucipara (1) & $63(38.4)$ & $61(47.3)$ & $1.44(0.90-2.30)$ & 0.128 \\
\hline & Grand multipara $(\geq 5)$ & $2(1.2)$ & $3(2.3)$ & $1.93(0.32-11.72)$ & 0.476 \\
\hline \multirow[t]{2}{*}{ Family size (F) } & $F<4$ & $98(59.8)$ & $55(42.6)$ & 1 & \\
\hline & $F \geq 4$ & $66(40.2)$ & $74(57.4)$ & $2.0(1.25-3.19)$ & 0.004 \\
\hline \multirow[t]{2}{*}{ Average monthly income (I) } & $I \geq 200$ USD & $142(86.6)$ & $71(55.0)$ & 1 & \\
\hline & $I<200$ USD & $22(13.4)$ & $58(45.0)$ & $3.2(1.33-3.54)$ & 0.002 \\
\hline \multirow[t]{2}{*}{ Distance to the hospital (D) } & $\mathrm{D}<10 \mathrm{~km}$ & $127(77.4)$ & $84(65.1)$ & 1 & \\
\hline & $D \geq 10 \mathrm{~km}$ & 37 (22.6) & $45(34.9)$ & $1.84(1.1-3.07)$ & 0.020 \\
\hline
\end{tabular}






Fig. 2 Classification according to gestational age at booking

(34.5\%). These reasons are similar to those in a study conducted in 2010 and 2017 in Nigeria and Ethiopia respectively where financial constraints where amongst the commonest reasons for late first ANC [11, 16]. Other reasons noted in other series but not found in our study included reasons such as she started ANC elsewhere [9]. The mean gestational age at first ANC attendance of 14 \pm 1.2 weeks means that most of the women present late for first ANC. Considering, that the first booking ANC is very important $f$ or localisation of pregnancy, screening of common anomalies and prevention of neural tube defects with folate, these minor anomalies may be missed as the mean gestational age of presentation is after the window period of $8-12$ weeks. This mean gestational age is similar to $15.9 \pm 3.7$ weeks and $17 \pm$ 5.3 weeks obtained by Girum et al. and Sh et al. respectively $[6,17]$.

The odds of starting ANC late was about 2 times higher if the participant live greater than $10 \mathrm{~km}$ from the hospital. This signifies that the further the patient lives away from the hospital, the more likely is the patient to start the first ANC late. This means patients in rural areas that are more likely to walk for long distances before getting to the hospital will most of the time present late for the first ANC. Recent studies in subSahara Africa earlier demonstrated that the odds of coming late for the first ANC were 2-5 times higher if the patient came from a rural area $[6,8,18]$. Also, the odds of coming late for first ANC was two times if the family size was greater than or equal to 4 persons. This means that as the size of the house gets larger the likelihood of attending ANC early drops. This can be explained by financial constraints which increases as the family size increases. This was earlier demonstrated in this study as about a third of those who came late their reasons were due to financial constraints. Recent series in sub-Sahara Africa have demonstrated similar results where the odds was $2-4$ times if the family size was $3-5$ $[6,8,18]$. The odds of starting first ANC late were 3 times higher if the woman had a monthly income less than 200 US dollars. 200 US dollars equals about 100,000 FRS which is the minimum amount of money needed for ANC registration and the initial prenatal investigations. This value is far above the minimum wage in Cameroon of 28.000 FRS per month. This signifies that most people whose wages in Cameroon are far above the minimum wage may still start ANC late. This is further confirmed by the fact that in this present study about a third of those who presented late had financial constraints. This is similar to studies obtained earlier in Ethiopia by Girum et al. [6] and Gebremeskel et al. [8] where monthly low income level was significantly associated with starting late starting of first ANC $[6,8]$.

Even though this study has come up with important finding with respect to late registration for first ANC visit, there are certain limitations worth mentioning here. Due to cross- sectional nature of the study temporal relationship could not be ascertained. The other concern was pregnant women who attended ANC at private health facilities and in rural areas are not included in the study. Moreover, gestational age was determined based on women's reports of their last menstrual period. In addition, our small sample size and single centre study limits it application. We therefore recommend that a larger multicentre cohort study be conducted to better describe the determinants of late first ANC attendance.

\section{Conclusion}

The study showed that nearly half of women starts their first ANC booking later than the WHO recommended time. Financial constraints and long distances to the hospital were major reasons advanced by about a third 
of those who presented late during the first ANC. Leaving more than $10 \mathrm{~km}$ away from the hospital, having a family size greater than or equal to 4 persons and having a lower monthly income less than 200 US dollars were factors significantly associated with late first antenatal care booking. Therefore addressing and empowering women through improving economic capacity and effective family planning are important measures to curb the problem.

\section{Abbreviations}

ANC: Antenatal care; DGH: Douala General Hospital; MMR: Maternal mortality rate

\section{Acknowledgements}

We express our sincere gratitude to all the patients who took part in this study. Much thanks also go to all the mid wives who participated in the monitoring of these patients during labour.

\section{Funding}

None

\section{Availability of data and materials}

The data sets supporting the conclusion of this study are available to the editor - in - chief upon reasonable request.

\section{Authors' contributions}

PNT wrote the protocol and designed the study; GEH corrected the protocol; PNT \& CN collected and analysed the data and wrote the initial manuscript; CBS, VAN, GEH \& PMT corrected and provided intellectual support to the initial manuscript; all authors approved the final manuscript and are responsible for it.

\section{Ethics approval and consent to participate}

Ethical approval was obtained from the ethical committee of Douala general hospital. A copy of is available for review upon request by the Editor-in-Chief of this journal. Written consent for participation was obtained from the patients.

\section{Consent for publication}

Not applicable

\section{Competing interests}

"The authors declare that they have no competing interests" in this section.

\section{Publisher's Note}

Springer Nature remains neutral with regard to jurisdictional claims in published maps and institutional affiliations.

\section{Author details}

${ }^{1}$ Faculty of Medicine and Biomedical Sciences, University of Yaounde 1, Yaounde, Cameroon. ${ }^{2}$ Obstetric and Gynaecology service, Douala General Hospital, Douala, Cameroon. ${ }^{3}$ Faculty of Health Sciences, University of Buea, Buea, Cameroon. ${ }^{4}$ Ibal Sub-Divisional Hospital, Oku, North West Region, Cameroon. ${ }^{5}$ Galactic Corps Research Group (GCRG), Buea, Cameroon.

${ }^{6}$ Muyuka District Hospital, Muyuka, Cameroon.

Received: 10 July 2017 Accepted: 14 November 2017

Published online: 13 December 2017

\section{References}

1. World Health Organization, UNICEF, United Nations, Department of Economic and Social Affairs, Population Division, World Bank. Trends in maternal mortality: 1990 to 2015: estimates by WHO, UNICEF, UNFPA, World Bank Group and the United Nations Population Division [Internet]. 2015 [cited 2017 Jun 18]. Available from: http:/www.who.int/reproductivehealth/ publications/monitoring/maternal-mortality-2015/en/.

2. Alkema L, Chou D, Hogan D, Zhang S, Moller A-B, Gemmill A, et al. Global, regional, and national levels and trends in maternal mortality between 1990 and 2015, with scenario-based projections to 2030: a systematic analysis by the UN maternal mortality estimation inter-agency group. Lancet. 2016; 387(10017):462-74.

3. Nino FS. Sustainable development goals - United Nations [Internet]. United Nations Sustainable Development. [cited 2016 Nov 22]. Available from: http:// www.un.org/sustainabledevelopment/sustainable-development-goals/.

4. World Health Organization, editor. WHO recommendations on antenatal care for a positive pregnancy experience. Geneva: World Health Organization; 2016. p. 152

5. Tolefac PN, Tamambang RF, Yeika E, Mbuagbaw L, Egbe TO. Ten years analysis of stillbirth in a tertiary hospital in sub-Sahara Africa: A case control study. BMC Research Notes. 2017;10(1). doi:10.1186/s13104-017-2787-2.

6. Girum T. Assessment of Timing of First Antenatal Care Visit and Associated Factors Among Pregnant Women Attending Antenatal Care in Dilla Town Governmental Health Institutions, Southern Ethiopia. Altern Integr Med 5: 220. doi: 10.4172/2327-5162.1000220.

7. Carroli G, Rooney C, Villar J. How effective is antenatal care in preventing maternal mortality and serious morbidity? An overview of the evidence. Paediatr Perinat Epidemiol. 2001;15:1-42.

8. Gebremeskel F, Dibaba Y, Admassu B. Timing of first antenatal care attendance and associated factors among pregnant women in Arba Minch town and Arba Minch District, Gamo Gofa zone, South Ethiopia. J Environ Public Health. 2015;2015:e971506

9. Kisuule I, Kaye DK, Najjuka F, Ssematimba SK, Arinda A, Nakitende G, et al. Timing and reasons for coming late for the first antenatal care visit by pregnant women at Mulago hospital, Kampala Uganda. BMC Pregnancy Childbirth. 2013;13:121

10. Gudayu TW, Woldeyohannes SM, Abdo AA. Timing and factors associated with first antenatal care booking among pregnant mothers in Gondar town; north West Ethiopia. BMC Pregnancy Childbirth. 2014;14:287.

11. Ndidi EP, Oseremen IG. Reasons given by pregnant women for late initiation of antenatal Care in the Niger Delta, Nigeria. Ghana Med J. 2010; 44(2):47-51.

12. Institut National de la Statistique. Enquête Démographique et de Santé et à Indicateurs Multiples (EDS-MICS) 2011 [Internet]. Yaounde, Cameroon; 2011 [cited 2017 Jun 20]. Available from: http://dhsprogram.com/pubs/pdf/ FR260/FR260.pdf.

13. Halle-Ekane GE, Obinchemti TE, J-LN N, Mokube NM, Njie MM, Njamen TN, et al. Assessment of the content and utilization of antenatal Care Services in a Rural Community in Cameroon: a cross-sectional study. Open J Obstet Gynecol. 2014;04(14):846.

14. Eng J. Sample size estimation: how many individuals should be studied? Radiology. 2003;227(2):309-13.

15. Aung TZ, Oo WM, Khaing W, Lwin N, Dar HT. Late initiation of antenata care and its determinants: a hospital based cross-sectional study. Int J Community Med Public Heal. 2017:3(4):900-5.

16. Gulema H, Berhane $\mathrm{Y}$. Timing of first antenatal care visit and its associated factors among pregnant women attending public health facilities in Addis Ababa, Ethiopia. Ethiop J Heal Sci. 2017;27(2):139-46.

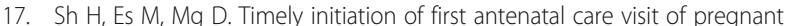
women attending antenatal care service. J Womens Heal Care. 2016;29:1-8.

18. Congo DR. Déterminants de la fréquentation tardive des services de soins prénatals dans les zones de santé de l'Equateur et du Katanga en République Démocratique du Congo. Ann Afr Med. 2011;4(4):845.

Submit your next manuscript to BioMed Central and we will help you at every step:

- We accept pre-submission inquiries

- Our selector tool helps you to find the most relevant journal

- We provide round the clock customer support

- Convenient online submission

- Thorough peer review

- Inclusion in PubMed and all major indexing services

- Maximum visibility for your research

Submit your manuscript at www.biomedcentral.com/submit
Ciomed Central 